Article

\title{
Mapping Entomological Dengue Risk Levels in Martinique Using High-Resolution Remote-Sensing Environmental Data
}

\section{Vanessa Machault ${ }^{1, *}$, André Yébakima ${ }^{2}$, Manuel Etienne ${ }^{2}$, Cécile Vignolles ${ }^{3}$, Philippe Palany ${ }^{4}$, Yves M. Tourre ${ }^{5}$, Marine Guérécheau ${ }^{1}$ and Jean-Pierre Lacaux ${ }^{1}$}

1 Laboratoire d'Aérologie, Observatoire Midi-Pyrénées (OMP), Université Paul Sabatier, Toulouse 31400, France; E-Mails: marine.guerecheau@telespazio.com (M.G.); jean-pierre.lacaux@aero.obs-mip.fr (J.-P.L.)

2 Service de Démoustication et de Lutte Anti-vectorielle, Conseil Général de la Martinique/Agence Régionale de Santé (SD-LAV), Fort-de-France, Martinique 97262, France;

E-Mails: yebakima@cg972.fr (A.Y.); manuel.etienne@cg972.fr (M.E.)

3 Direction de la Stratégie et des Programmes/Terre-Environnement-Climat, Centre National d'Etudes Spatiales (CNES), Toulouse 31400, France; E-Mail: cecile.vignolles@cnes.fr

4 Météo-France Direction Inter-Régionale Antilles-Guyane, Fort-de-France, Martinique 97888, France; E-Mail: philippe.palany@meteo.fr

5 Lamont-Doherty Earth Observatory (LDEO) of Columbia University, Palisades, New York, NY 10964-1000, USA; E-Mail: yvestourre@aol.com

* Author to whom correspondence should be addressed; E-Mail: vanessamachault@yahoo.com.br.

External Editors: Fazlay S. Faruque and Wolfgang Kainz

Received: 10 September 2014; in revised form: 6 November 2014 / Accepted: 25 November 2014 / Published: 10 December 2014

\begin{abstract}
Controlling dengue virus transmission mainly involves integrated vector management. Risk maps at appropriate scales can provide valuable information for assessing entomological risk levels. Here, results from a spatio-temporal model of dwellings potentially harboring Aedes aegypti larvae from 2009 to 2011 in Tartane (Martinique, French Antilles) using high spatial resolution remote-sensing environmental data and field entomological and meteorological information are presented. This tele-epidemiology methodology allows monitoring the dynamics of diseases closely related to weather/climate and environment variability. A Geoeye-1 image was processed to extract landscape elements that could surrogate societal or biological information related to the life cycle of Aedes vectors. These elements were subsequently included into statistical
\end{abstract}


models with random effect. Various environmental and meteorological conditions have indeed been identified as risk/protective factors for the presence of Aedes aegypti immature stages in dwellings at a given date. These conditions were used to produce dynamic high spatio-temporal resolution maps from the presence of most containers harboring larvae. The produced risk maps are examples of modeled entomological maps at the housing level with daily temporal resolution. This finding is an important contribution to the development of targeted operational control systems for dengue and other vector-borne diseases, such as chikungunya, which is also present in Martinique.

Keywords: dengue; remote-sensing; risk mapping; Aedes aegypti; medical entomology

\section{Introduction}

Dengue is an infectious disease caused by one of the four serotypes (DEN-1 to DEN-4) of the dengue virus. It is transmitted by the bite of infected Aedes female mosquitoes and primarily occurs in urban areas. Even if the mortality rate is low among human populations, dengue is considered as one of the most important mosquito-borne viral disease due to its extensive geographic spread (125 endemic countries) with 50 to 200 million annual infections [1].

In Martinique (French Antilles), six dengue epidemic waves occurred during the last 20 years. More than 41,000 clinical cases were reported during the penultimate epidemic in 2010, accounting for approximately $10 \%$ of the island population. In this region, the Aedes aegypti mosquito is the single identified vector for the transmission of dengue virus to date. This mosquito breeds mostly in artificial domestic or peridomestic containers filled with clean water with little organic debris and low concentrations of inorganic nutrients [2,3]. In Martinique, potential breeding sites include (i) flower pots with saucers, detritus, and debris, abandoned cars and tires, badly maintained gutters, discarded old domestic appliances or pools that may be all filled-up naturally with rainfall; (ii) containers such as drum barrels that may be deliberately placed under gutters or in yards to collect rain water for watering/cleaning purposes; (iii) rarely, containers that can be artificially filled-up when watering. Antivectorial and mosquito nuisance control are managed by a public organization (Service de Démoustication et de Lutte Antivectorielle, SD-LAV). Since 1991, the SD-LAV has collected information on dengue vectors with an additional effort during outbreaks.

No specific treatment is available for dengue, and no operational vaccine is currently available [4]. Controlling virus transmission thus mainly consists of integrated vector management: (i) information is provided to the inhabitants to avoid the creation of potential larval habitats; (ii) source reduction occurs via the physical destruction of the potential/positive breeding sites; and (iii) insecticide spraying mainly occurs during epidemics. It is also important to note that it has been shown that for dengue vectors, "targeting only the most productive water container types (roughly half of all water holding container types) was as effective in lowering entomological indices as targeting all water holding containers at lower implementation costs" [5]. In this context, good knowledge of the entomological conditions in a given area and during a given period of time is a prerequisite for implementing efficient control. Unfortunately, entomological data are seldom collected longitudinally, and available data often 
provide only a snapshot of a rather continuous phenomenon. Risk maps at appropriate scales can provide surrogate data and valuable information regarding a spatio-temporal evaluation of entomological risk. Mapping at global scales may co-exist with fine scale or local mapping to establish local control strategies.

From global/regional to local scales, the heterogeneity of spatial and temporal distributions of dengue vectors/cases is partly led by weather/climate conditions (e.g., rainfall amount, relative humidity, and temperature), environment/landscape (e.g., vegetation and soil types) or human activities (e.g., transportation, urbanization, and waste management). Subsequent modeling of entomological/epidemiological dengue risk may benefit from the use of remote-sensing (RS) information that may provide appropriate ecological, meteorological, and geographic outputs. Choices may be made among available satellite products at various temporal, spectral, and spatial scales. In recent years, satellite products have been used to map numerous vector-borne diseases [6-10], and these products were recently proven to provide useful information for modeling Aedes aegypti or Aedes albopictus distribution [11-19], human dengue cases distribution [20,21] or the potential for future dengue vector or disease expansion [22-24].

The present study involves mapping the risk of the presence of Aedes aegypti immature stages around houses. This condition is necessary but not sufficient for dengue fever emergence given the numerous factors interplaying between the presence of Aedes larvae and dengue cases (rate of adult mosquito emergence, human-vector contact, human population movements, and acquired immunity to circulating serotype). Indeed, it has been argued that "mapping and spatial modeling based on mosquito presence or abundance data should be viewed as only representing potential dengue risk" [25]. Therefore, the larval maps of the present study will be referred to as "entomological dengue risk maps". Recipients of such maps should include the vector managing units that subsequently focus control interventions in places and times where/when the risk of vector presence is highest.

The practical and conceptual approach of tele-epidemiology could then be applied to the spatio-temporal mapping of entomological dengue risk in urban settings in Martinique. It has been developed and patented by the French Spatial Agency (CNES) and its partners [26,27]. The approach involves monitoring and studying the spatio-temporal dynamics of human and animal diseases that are closely related to weather/climate and environment variability. It relies on the identification of an experimental unit, which serves as the "object" that must be identified/characterized to properly assess the levels of risk. This unit is based on the sound knowledge of the biological and physical processes that underline the presence/densities of immature and adult vectors. It is thus widely dependent upon the disease being investigated. For example, this experimental unit is a pond ( $\sim 1$ ha) when studying Rift Valley Fever entomological risk [28] and a water body or aggregates of small water bodies ( $\sim 0.1 \mathrm{ha}$ ) when studying urban malaria entomological risk [29]. Then, appropriate choices of satellite data and dynamic models must be assessed along with extensive use of in situ measurements.

Three observations underpinned the present study. Firstly, if the potential Aedes aegypti breeding habitats could not be directly detected using satellite images even at very high spatial resolution, their specific environment could be mapped. Indeed, the dwelling and yard conditions may reflect local habits regarding the maintenance of private yards/gardens and their close surroundings that may be associated with the presence of containers that retain water. Secondly, estate characteristics (i.e., shading and tidiness of a house and its yard) have been identified as determinants of the presence/abundance of Aedes aegypti immature stages and eggs [18,30-32]. Thus, the characterization of fine-scale 
environments could provide information on the risk factors for the presence of dengue vector immature stages in areas where containers are present. Thirdly, meteorological conditions mainly drive the temporal dynamics for container filling as well as entomological dynamics (e.g., eggs hatching and larvae development). Consequently, the experimental unit here has been defined as the house with its nearby environment studied on one specific date. The state of such units was then described with details at the field level (i.e., ground entomological investigations), meteorological level (high temporal resolution ground observation station), and environmental level (i.e., high spatial resolution RS data). The main objective here was to model in space and time the houses considered to be so-called "positive" for Aedes aegypti immature stages from 2009 to 2011 in Tartane (Martinique, French Antilles) by using RS environmental data and field meteorological information. This modeling was performed to produce high spatio-temporal resolution dengue entomological risk maps.

\section{Multi-Disciplinary Data and Methods}

\subsection{Studied Site and Period}

The city of Tartane $\left(14^{\circ} 45^{\prime} 29.24^{\prime \prime} \mathrm{N}, 60^{\circ} 55^{\prime} 10.56^{\prime \prime} \mathrm{W}\right)$ belongs to the Caravelle Peninsula, which is located northeast of Martinique. This area has historically served as a fishing cove with small and low-rise dwellings surrounded by small gardens or yards. The city center is near the seaside, whereas other sections are located uphill. The population is made up of $\sim 3000$ inhabitants. The area is a tourist attraction and includes many vacation accommodations. The studied site is approximately $8 \mathrm{~km}^{2}$ (Figure 1). Several dengue outbreaks, including one that occurred in 2010, have started in Tartane, possibly due to favorable entomological conditions [33]. Although dengue epidemics "typically" last from July to December, viral circulation in 2010 was noted in early February, peaked in June and lasted until the end of the year. The studied period thus included this epidemic and ran from June 2009 to August 2011.

Figure 1. The Martinique Island, the studied area, and the six studied sections (black rectangles numbered 1 to 6 ) on the Tartane Peninsula.

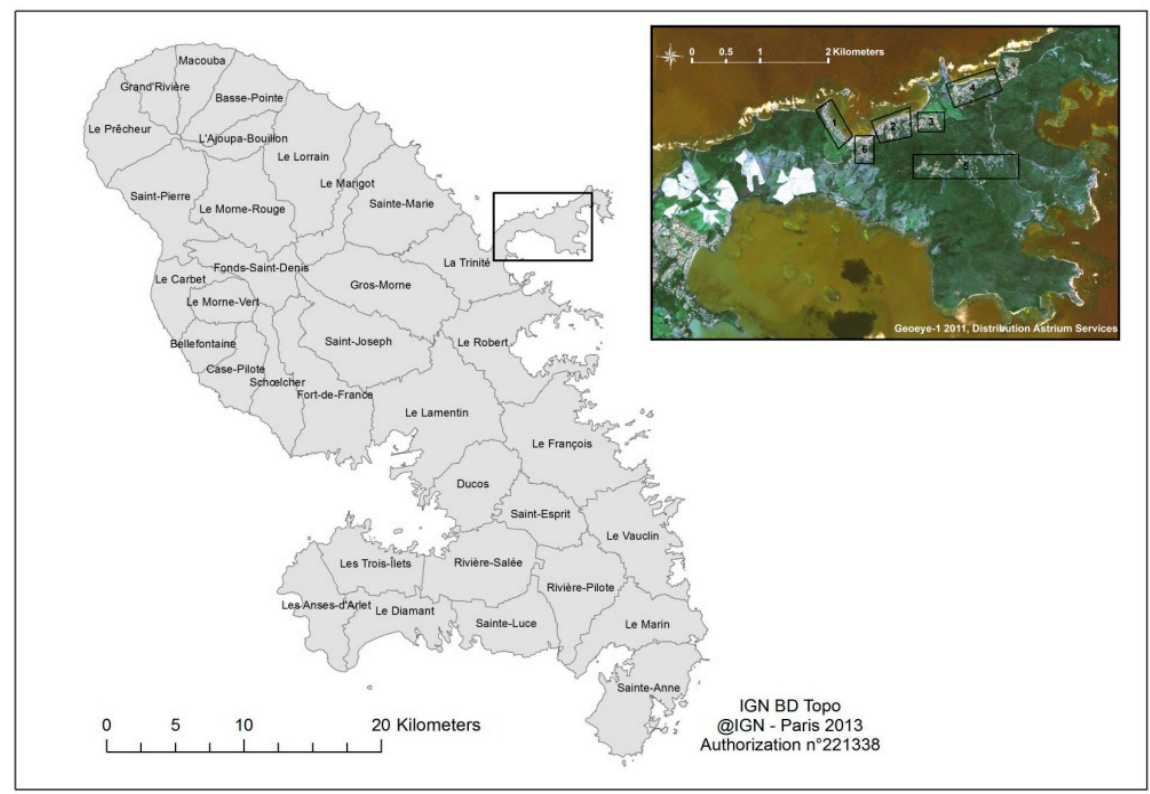




\subsection{Entomological Data}

The SD-LAV conducts entomological surveillance in Martinique and thus regularly records mosquito information in the houses of the island municipalities [34]. All of the available records were selected from the SD-LAV databases for the studied period and area. Each record was associated with a given inhabited house visited on one of the following dates: 19/06/2009, 01/10/2009, 22/10/2009, 09/11/2009, 22/02/2010, 23/02/2010, 05/03/2010, 23/08/2011, 29/09/2010, and 02/12/2012. The records contained information regarding the number and type of domestic and peridomestic containers as well as the presence of Aedes aegypti immature stages (i.e., all larvae stages and pupae). As the records did not contain geographic coordinates, only the records that could have been retrospectively plotted with a global positioning system (GPS) were maintained in the final database. Plotting was performed during July 2012 by the operators who conducted the 2009-2011 ground surveys and was based on the recorded name of the inhabitant and a deep knowledge of the area. Types of domestic or peridomestic containers include drum barrels, tanks, waste-bins, flower pots and saucers, gutters, tires, discarded appliances, and pools. Sampled houses are positioned in Figure 2. From their spatial distribution, six sections were identified as shown in Figure 1.

Figure 2. Map of the sampled houses.

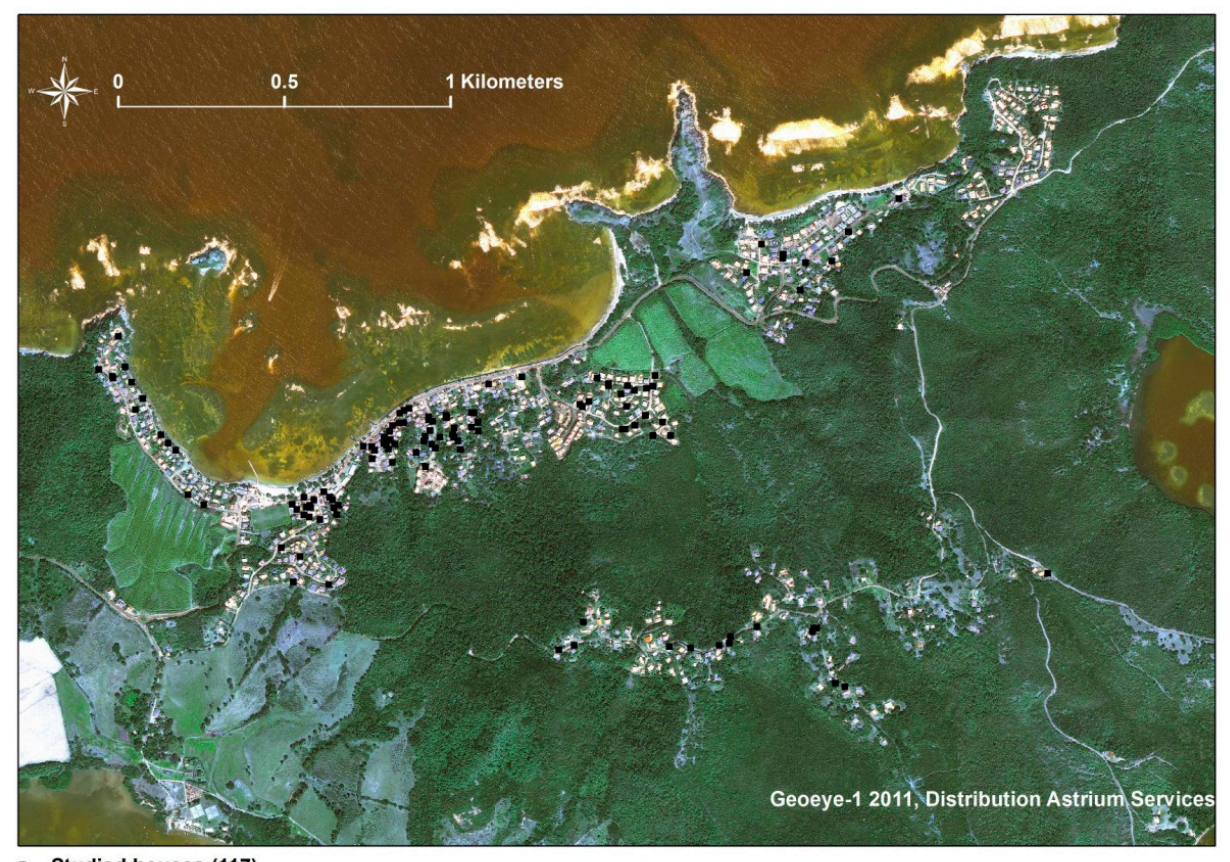

- Studied houses (117)

The ten different dates covered different seasons of the year. A total of 117 houses were visited (i.e., 88 houses visited once, 18 twice, 10 thrice and one visited four times), representing approximately $12 \%$ of the total number of houses in the studied area. Thus, the number of observations, i.e., experimental units, was 158. A total of 88 out of those 158 experimental units were positive for the presence of peridomestic water-filled containers (from one to 11 containers per house at a given date). Thirty experimental units were Aedes larvae-positive (19\% of all experimental units and $34 \%$ of all water-positive experimental units). Among all types of water-filled containers, large containers and drum barrels were most frequently identified as Aedes larvae positive with 57\% and 
$51 \%$ positive observations, respectively. These containers were noted at $82 \%$ of the total number of positive breeding sites.

\subsection{Meteorological Data}

In Martinique, the summer rainy season (July to November) is characterized by frequent and heavy rainfall and maximum temperatures of approximately $32{ }^{\circ} \mathrm{C}$, whereas the dry season (February to April) exhibits maximum temperatures of approximately $30^{\circ} \mathrm{C}$. These seasons are separated by two intermediate seasons. Rainfall amounts are heterogeneous on the island, ranging from approximately $1500 \mathrm{~mm}$ to greater than $4000 \mathrm{~mm}$ in the mountainous area. The year 2009 was exceptionally hot with minimal rainfall except on the Atlantic coastline. In 2010, temperatures were also high particularly during February and March. February was almost completely dry. Heavy precipitation started in early June followed by a very dry period. Again, the year 2011 experienced hot temperatures. However, 2011 was the wettest year of the 2009-2011 period with basically no dry season.

Daily temperature and humidity (minimum, maximum, and mean values) as well as precipitation amounts were provided for the present study by Météo-France. They were recorded at the observing station located in the Caravelle Peninsula. Yearly precipitation levels recorded during 2009, 2010, and 2011, were $948 \mathrm{~mm}, 1408 \mathrm{~mm}$, and $1823 \mathrm{~mm}$, respectively. Several variables were calculated from the raw data, added to the entomological database, and matched according to the date of the ground surveys as follows:

- $\quad$ total rainfall amount for the 2-, 3-, 4-, ..., to 30-day period before each entomological ground investigation date;

- $\quad$ average of temperature and relative humidity for the 2-, 3-, 4-, ..., to 15-day period before each entomological ground investigation date.

\subsection{Satellite Images and Environmental Data}

A Geoeye-1 optical image with clear sky was acquired on 13/03/2011. Data included four spectral bands at a $0.41-\mathrm{m}$ spatial resolution (blue, green, red, and near infrared). The image was projected in WGS 84, UTM Zone $20 \mathrm{~N}$ and geometrically corrected using the 50-m spatial resolution elevation map (IGN BD $\mathrm{ALTI}^{\circledR}$ ) from the French National Geographic Institute IGN (Institut National de l'Information Géographique et Forestière). Image processing was performed using ENVI 4.8 and ENVI EX (Exelis Visual Information Solutions). Other available geographic data included IGN topographic map (IGN BD TOPO $^{\circledR}$ ) and cadastral map (IGN BD ADRESSE ${ }^{\circledR}$ ). Slope and objects height maps at $1-\mathrm{m}$ spatial resolution were available through Litto3D ${ }^{\circledR}$ (IGN, Service Hydrographique et Océanographique de la Marine, Direction de l'Environnement, de l'Aménagement et du Logement-Martinique, Agence des Aires Marines Protégées), which was produced from airborne LIDAR measurements.

Three vegetation and soil indicators were derived from the Geoeye-1 image (Table 1). 
Table 1. Environmental indicators calculated from the Geoeye-1 image at 0.41-m spatial resolution.

\begin{tabular}{|c|c|c|}
\hline Environmental Indicator & Spectral Bands Combination * & Description \\
\hline $\begin{array}{l}\text { NDVI (Normalized } \\
\text { Difference Vegetation } \\
\text { Index) }[35,36]\end{array}$ & $\frac{N I R-\text { red }}{N I R+\text { red }}$ & $\begin{array}{l}\text { Values increase with the presence and } \\
\text { density of vegetation. A value superior to } \\
0.2 \text { typically corresponds to a vegetated area. } \\
\text { Negative values indicate non-vegetated } \\
\text { features, such as barren surfaces (rocks and } \\
\text { soils), water, built-up areas or asphalt. }\end{array}$ \\
\hline $\begin{array}{l}\text { NDWI Mac Feeters } \\
\text { (Normalized Difference } \\
\text { Water Index) [37] }\end{array}$ & $\frac{\text { green }-N I R}{\text { green }+N I R}$ & $\begin{array}{l}\text { It delineates open water features while } \\
\text { eliminating the presence of soil and terrestrial } \\
\text { vegetation features. Values increase with the } \\
\text { presence of water and decrease with the } \\
\text { presence of vegetation. }\end{array}$ \\
\hline $\begin{array}{l}\text { ANDWI (Adapted NDWI } \\
\text { Mac Feeters Index) }\end{array}$ & $\frac{\text { blue }- \text { NIR }}{\text { blue }+ \text { NIR }}$ & $\begin{array}{l}\text { Using the blue band, this adapted NDWI Mac } \\
\text { Feeters maximizes the detection of water. }\end{array}$ \\
\hline
\end{tabular}

* NIR: Near infrared; SWIR: Short wave infrared.

A three-step classification procedure was applied to produce the Land Use and Land Cover (LULC) map of the studied area. Firstly, a supervised maximum likelihood pixel-based classification was performed in ENVI 4.8 based on a set of training areas covering $5.4 \%$ of the total surface of the image. For each identified LULC class, a set of training polygons were digitized by an operator who photo-interpreted the Geoeye-1 image. The spectral signature of each class was then built by the software. Each pixel was assigned to the class having the highest probability to be the correct one based on those spectral signatures. No exclusion threshold was defined, so every pixel of the studied zone was classified. Some validation regions were also digitized, and they covered $4.7 \%$ of the image total area. They were used to calculate the kappa coefficient, which provides a measurement of the classification accuracy. This coefficient was 0.91 , indicating a good agreement between the resulting LULC classes and the validation areas. Secondly, as improvements could be expected in the classification accuracy of some elements of the landscape, an object-oriented classification was performed. Segmentation, merging objects, and implementation of rules (area, convexity, average values of bands...) were undertaken in the ENVI EX Feature Extraction module. The quality of this classification was assessed by photo-interpretation, and it was thus concluded that the roofs and the swimming pools were accurately classified. Thirdly, a final classification was produced by merging both pixel and object classifications using a decision tree. It included fourteen land-cover classes: i.e., five for vegetation, including "trees", "sugar cane", "stubbles", "lawn", "sparsely vegetated soil", five different types of roofs, "sand", "asphalt", "swimming pools", and "sea/ocean". A merged class for all roof types was also created. 


\subsection{Geographic Information System (GIS)}

A GIS was built using ArcGIS 10.0 (Environmental Research Systems Institute, Redlands, CA, USA) to characterize the experimental units defined in the Introduction. All 117 surveyed houses were plotted, and environmental indices, LULC map, and elevation data were added as geo-referenced layers. Each single house of the Caravelle Peninsula was isolated as an object based on the LULC map. The plot around each house was identified using the IGN cadastral map.

Environmental variables, i.e., the minimum/maximum/mean for the three indices, the slope and the object height and the areas of each LULC class, were computed for each surveyed house. This was accomplished for each plot and for the 50-m and 100-m radius buffer zones around the individual houses. The Euclidian distance from the house to the first patch of each LULC class as well as the area of houses (assumed equal to the area of their roofs) and plots were calculated. These data were merged with the entomological database for each house.

\subsection{Modeling Strategy}

The overall database included the entomological, environmental, and meteorological variables described above. Each record was associated with one house visited on one date, i.e., with one experimental unit. The chosen scenario (Figure 3) included the following two steps that involved the investigation of driving environmental and meteorological factors:

- Step 1: the presence of one or several water-filled container(s) in the vicinity of a house at a given date, independently of the presence or not of Aedes aegypti immature stages. This involved the detection of the water-positive experimental units;

- Step 2: the presence of Aedes aegypti immature stages exclusively in the experimental units that held one or several water-filled container(s). This involved the detection of the Aedes larvae-positive experimental units. No reference to the larval density was included.

Given that the number of domestic water containers was very low in the area, only the peridomestic containers were considered.

Figure 3. Scenario retained for dengue entomological risk mapping.

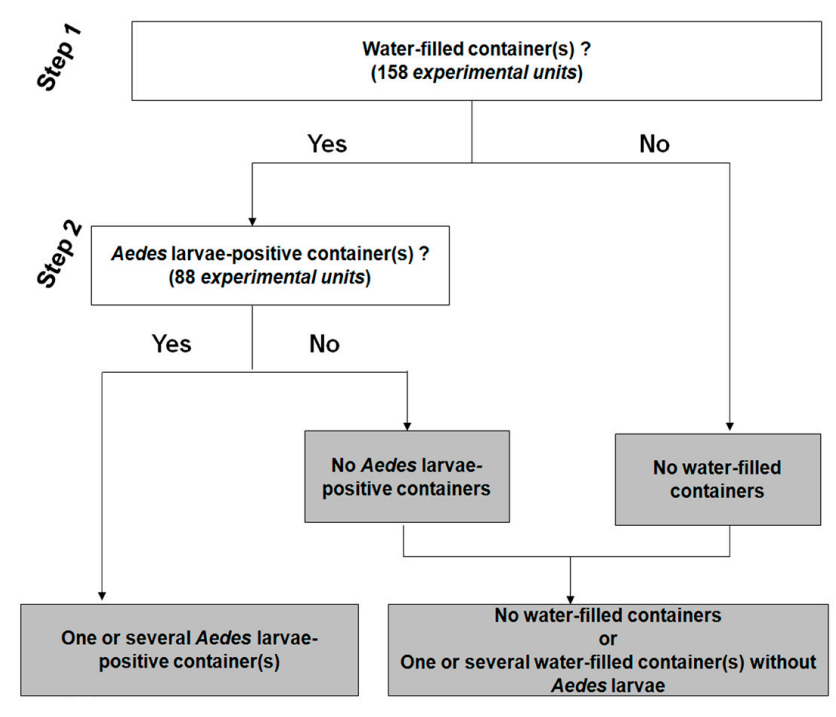




\subsection{Statistical Analysis and Risk Mapping}

Statistical analyses were performed using Stata 11 (Stata Corporation, College Station, TX, USA). Logistic regression analyses to explain the outcomes from both steps above were fitted at the experimental unit level using environmental and meteorological indicators as possible explanatory variables. For each model, uncorrelated variables with $p$-values $<0.25$ from univariate analyses were candidates for multivariate analyses. Selection among the high number of co-linear variables, i.e., meteorological and environmental variables that were created at several time and space scales, was performed by minimizing the AIC (the Akaike Information Criterion) in univariate analysis as well as by choosing variables with the best biological input. A manual backward stepwise selection procedure was applied in the final model to select variables with $p$-values $<0.05$. The sampling scheme implied that some autocorrelations could exist between observations given that nearby observations could be more similar than distant ones due to the presence of more similar surroundings. In the case that the local environment was not fully considered by the explanatory variables, a random effect was added to the models at the level of the section. Model validity was assessed using the full sample and Receiver Operating Characteristic (ROC) curve (i.e., representation of sensitivity against 1-specificity or true positive rate versus false positive rate, thereby providing the discriminative value of a test). It should be noted that the small amount of observations did not allow validity assessment of the models with a subset of observations. The cut-off value was chosen to maximize sensitivity and specificity. Robustness was assessed using six sub-models of each final model fitted by separately omitting the experimental units of each section.

The linear equations derived from the final models allowed for the prediction of outcomes at the non-surveyed experimental units, i.e., other Tartane houses and dates other than the dates of the surveys. We have chosen to undertake mapping for each day of the 2010 year to visualize the seasonal variability. The explanatory variables of the final models (Steps 1 and 2) were extracted from the GIS for every single building of the area. Meteorological independent variables that were significantly associated with the outcomes were calculated for each day of 2010. Then, the equation of Step 2 was applied to the buildings that were predicted as water positive in Step 1. The results were daily maps of the houses harboring Aedes larvae-positive container(s). These maps were merged into composite monthly maps that included the number of days for which each house was predicted to be Aedes larvae positive.

\section{Results and Discussion}

\subsection{Results}

\subsubsection{Step 1. Modeling the Water-Positive Experimental Units}

In univariate analysis, several environmental and meteorological variables were significantly associated with the presence of water-filled container(s) in the experimental units. These environmental parameters included the area of the class "sparsely vegetated soil" in the plot, area of the class "tiled roof" in the plot, area of the class "swimming pool" within a 50-m buffer, slope of the plot, mean object height in the 100-m buffer (with positive sign), as well as area of the class "lawn" within the 
50-m buffer, area of the class "sand" within the 50-m buffer and distance to the class "sparsely vegetated soil" (with negative sign). Some rainfall, temperature, and humidity variables were also positively or negatively associated with the presence of one or several water-filled container(s) in an experimental unit.

In multivariate analysis, the area of the class "sparsely vegetated soil" in the plot and the total rainfall during the 4-day period before the day of the field visit were positively associated with the outcome, whereas the area of the class "lawn" within the 50-m buffer around the house was negatively associated with the outcome (Table 2). The section random effect was not statistically significant in the final model. In addition, the six sub-models fitted by separately omitting the experimental units of each section provided similar coefficients compared with the final model. The area under the ROC curve was 0.72 (95\% confidence interval: $0.64-0.80)$. A total of 103 experimental units out of 158 were correctly predicted $(65 \%)$. The sensitivity was $63 \%$, and the specificity was $69 \%$. The positive predictive value was $71 \%$, and the negative predictive value was $59 \%$.

Table 2. Remote-sensing environmental and ground meteorological variables significantly associated with water-positive experimental units. Multivariate logistic regression analyses with section random effects are provided (Step 1).

\begin{tabular}{lccc}
\hline \multicolumn{1}{c}{ Explanatory Variables } & Coefficient & 95\% Confidence Interval & $p$-Value \\
\hline \multicolumn{4}{c}{ 158 Experimental Units, 6 Sections } \\
\hline $\begin{array}{l}\text { Surface of the class "sparsely vegetated soil" } \\
\text { in the house plot (per 10 } \mathrm{m}^{2} \text { ) }\end{array}$ & 0.10 & {$[0.02 ; 0.19]$} & 0.017 \\
\hline $\begin{array}{l}\text { Surface of the class "lawn" within the 50-m } \\
\text { buffer around the house (per } 100 \mathrm{~m}^{2} \text { ) }\end{array}$ & -0.10 & {$[-0.17 ;-0.03]$} & 0.007 \\
\hline $\begin{array}{l}\text { Total rainfall during the 4-day period before } \\
\text { field visit (per 10 mm) }\end{array}$ & 0.26 & {$[0.07 ; 0.46]$} & 0.007 \\
\hline section random effect & & & 0.498 \\
\hline
\end{tabular}

\subsubsection{Step 2. Modeling the Aedes Larvae-Positive Experimental Units}

In univariate analysis, several environmental and meteorological variables were associated with the presence of Aedes larvae-positive container(s) in the experimental units that held water-filled container(s). Those environmental variables included area of the class "tree" within the 50-m buffer, mean height of the houses within the 50-m buffer, mean NDVI within the 50-m buffer (with positive sign), as well as area of the class "asphalt" within the 50-m buffer, area of the class "swimming pool" within the 50-m buffer, and area of the class "tiled roof" within the 50-m buffer (with negative sign). Some rainfall, temperature, and humidity factors were also positively or negatively associated.

In multivariate analysis, the mean of the maximum humidity recorded during the 5-day period before the day of the ground investigation was positively associated with the outcome, whereas the area of the class "asphalt" within the 50-m buffer around the house was negatively associated (Table 3). The section random effect was not statistically significant in the final model. In addition, the six sub-models fitted by separately omitting the experimental units of each section provided very similar coefficients compared with the final model. The area under the ROC curve was 0.74 ( $95 \%$ confidence interval, 0.63-0.86). A total of 64 experimental units out of 88 were correctly predicted (73\%). 
The sensitivity was $70 \%$, and the specificity was $74 \%$. The positive predictive value was $58 \%$, and the negative predictive value was $83 \%$.

Table 3. Remote-sensing environmental and ground meteorological variables significantly associated with Aedes larvae-positive experimental units among units that hold water-filled container(s). Multivariate logistic regression analyses with section random effects are provided (Step 2).

\begin{tabular}{llcc}
\hline \multicolumn{1}{c}{ Explanatory Variables } & Coefficient & 95\% Confidence Interval & p-Value \\
\hline \multicolumn{4}{c}{$\mathbf{8 8 ~ E x p e r i m e n t a l ~ U n i t s , ~ 6 ~ S e c t i o n s ~}$} \\
\hline $\begin{array}{l}\text { Surface of the class "asphalt" within the 50-m } \\
\text { buffer around the house (per 100 } \mathrm{m}^{2} \text { ) }\end{array}$ & -0.10 & {$[-0.17 ;-0.04]$} & 0.003 \\
\hline $\begin{array}{l}\text { Mean of maximum humidity during the 5-day } \\
\text { period before field visit (per 1\%) }\end{array}$ & 0.27 & {$[0.07 ; 0.48]$} & 0.008 \\
\hline section random effect & & & 0.209 \\
\hline
\end{tabular}

\subsubsection{Application of the Scenario (Step 1 + Step 2)}

Final predictions from the chosen scenario are displayed in Table 4. A total of 132 experimental units out of 158 were correctly predicted (84\%). The sensitivity was $57 \%$, and the specificity was $90 \%$. The percentage of correctly classified predictions ranged from $67 \%$ to $92 \%$ depending on sections. The positive predictive value was $57 \%$, and the negative predictive value was $90 \%$ (false positive rate $=43 \%$; false negative rate $=10 \%$ ).

Table 4. Final predictions of the scenario versus field data: number of Aedes larvae-positive experimental units versus number of Aedes larvae-negative experimental units.

\begin{tabular}{llccc}
\hline \multicolumn{4}{c}{ Prediction from Scenario } & \\
\hline \multirow{5}{*}{ Field Data } & $\begin{array}{c}\text { Number of } \text { Aedes } \\
\text { Larvae-Negative } \\
\text { Experimental Units }\end{array}$ & $\begin{array}{c}\text { Number of } \text { Aedes } \\
\text { Larvae-Positive } \\
\text { Experimental Units }\end{array}$ & Total \\
\cline { 2 - 5 } & $\begin{array}{l}\text { Number of Aedes larvae-negative } \\
\text { experimental units }\end{array}$ & $\mathbf{1 1 5}$ & 13 & 128 \\
\cline { 2 - 6 } & $\begin{array}{l}\text { Number of Aedes larvae-positive } \\
\text { experimental units }\end{array}$ & 13 & $\mathbf{1 7}$ & 30 \\
\cline { 2 - 5 } & Total & 128 & 30 & 158 \\
\hline
\end{tabular}

\subsubsection{Predictive Entomological Risk Mapping in Tartane}

Both steps of the scenario were successfully applied to every building (983) of the studied area at each day of the 2010 year to generate high spatio-temporal resolution entomological risk maps. The resulting composite monthly maps are displayed in Figure 4 and Supporting Information. None of the buildings was predicted as being Aedes larvae-positive for $100 \%$ of the days in 2010. A total of 126 buildings were predicted to have less than 10 Aedes larvae-positive days in the year, among which 28 were predicted to always be negative for Aedes larvae ( 0 positive days in the year). Maximum entomological risk was found in section 5 (see Figure 1, top right corner). The risk was decreased in 
sections 1, 2 and 4 (same risk) as well as sections 6 and 3 (see Figure 1, top right corner) with yearly figures among the sections ranging from $77 \%$ to $15 \%$ Aedes larvae-positive experimental units. June and September 2010 exhibited the highest predicted entomological risk (45\% and 44\%, respectively, of the number of experimental units were predicted as Aedes larvae positive), whereas February and December were predicted with the lowest risk $(17 \%$ and $18 \%$, respectively, of the number of experimental units were predicted as Aedes larvae positive).

Figure 4. Monthly entomological risk maps from the modeling experiment based on data from January until December 2010. The number of predicted Aedes larvae-positive days for the 983 buildings within the studied area is provided (see color code at bottom left).
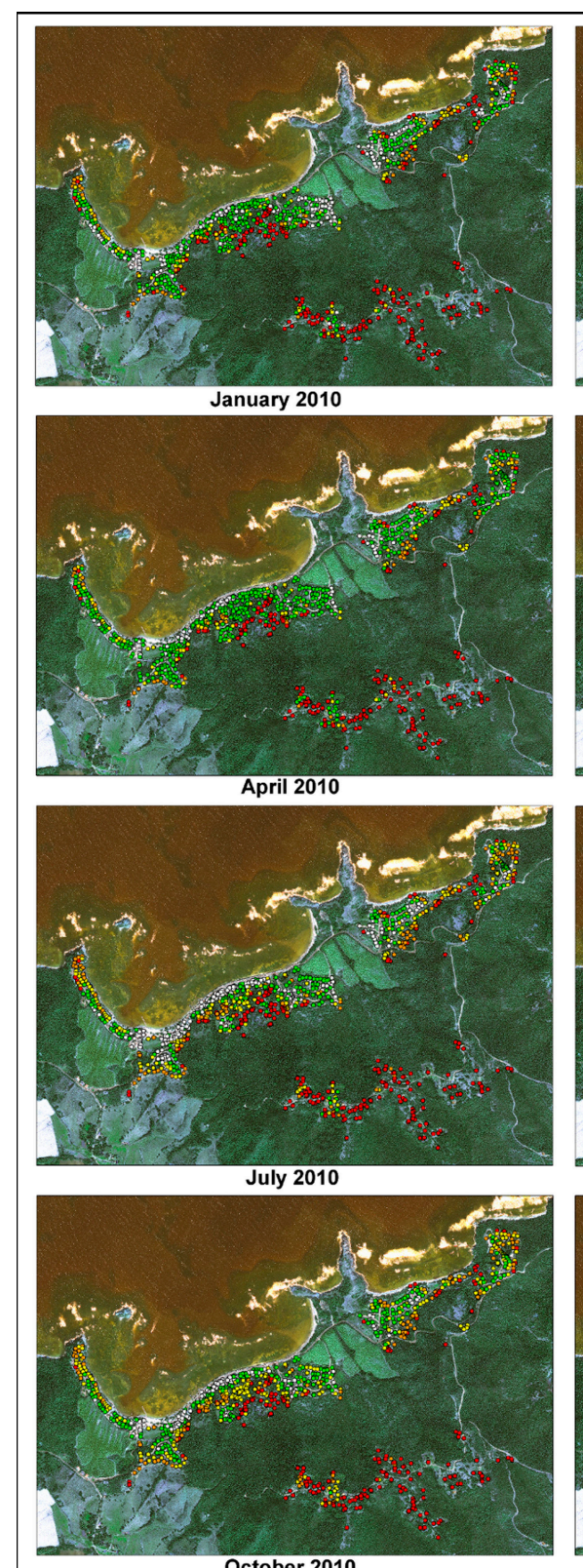

October 2010

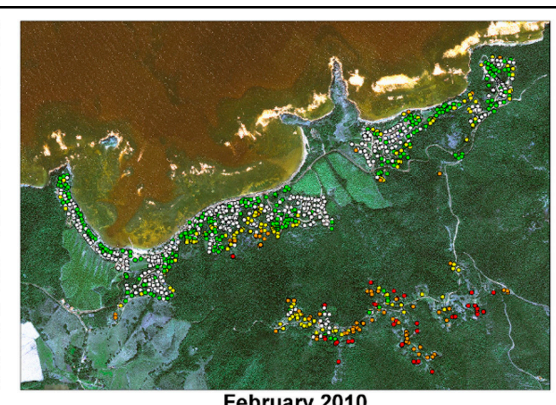

February 2010

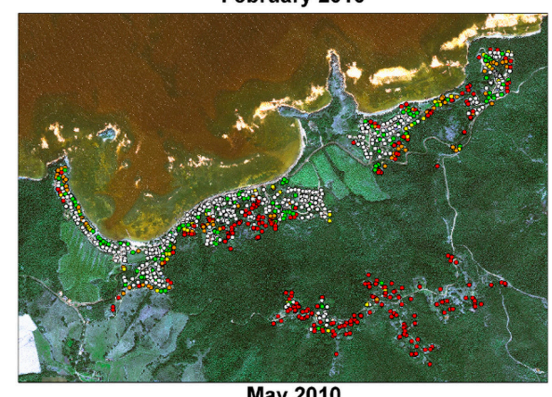

May 2010

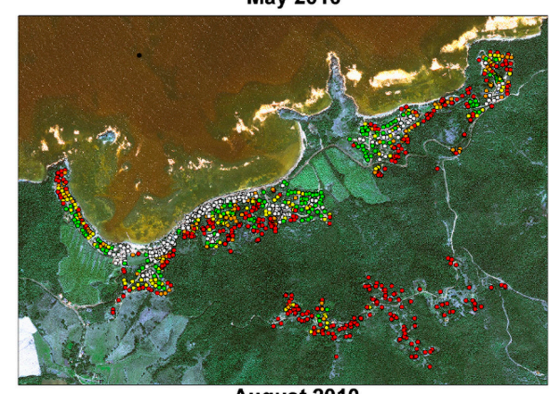

August 2010

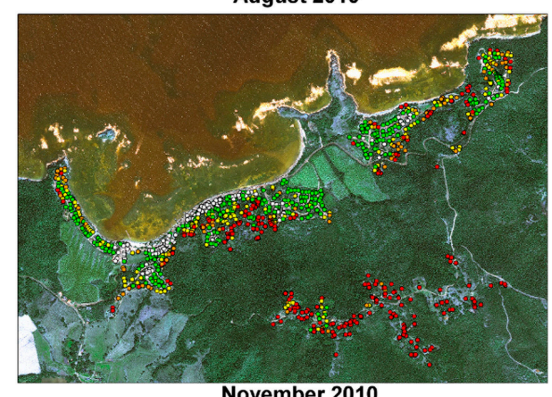

November 2010

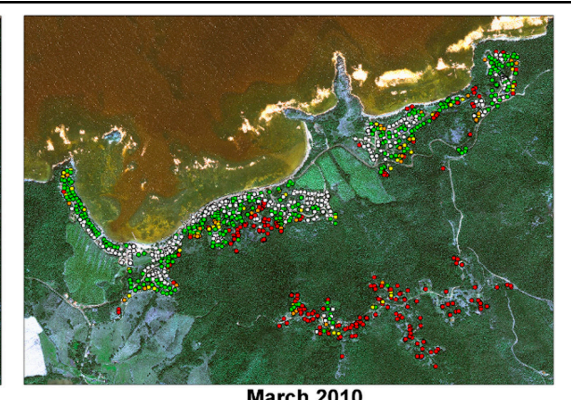

March 2010

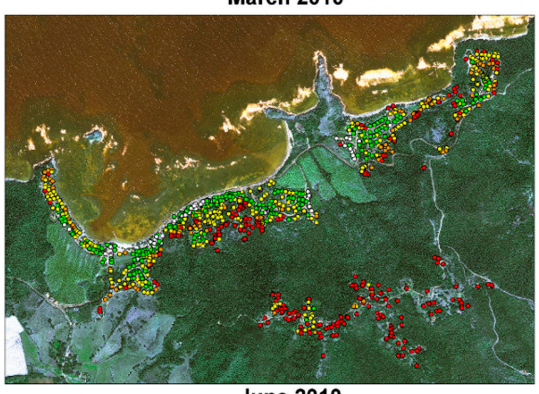

June 2010
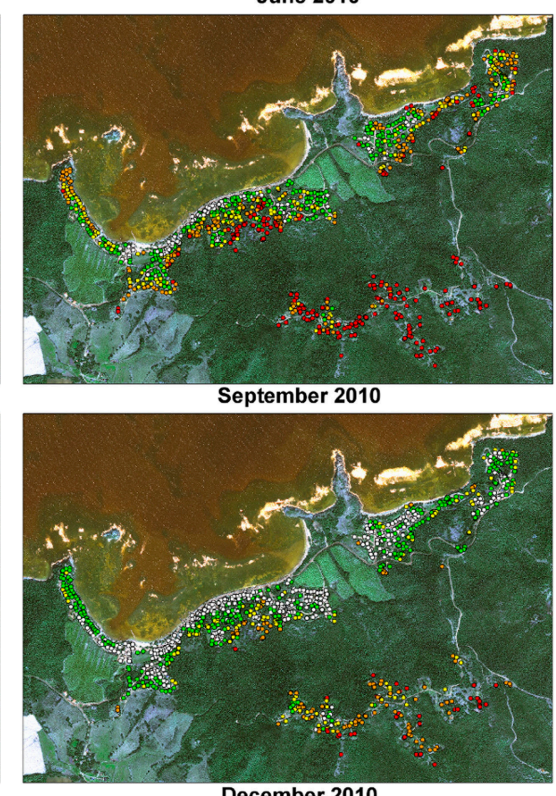

December 2010

Monthly number of predicted 'Aedes larvae-positive' days at the level of houses:

- 0 days

- $1-7$ days

- 8 - 14 days

- $15-21$ days

- 22 - 31 days

年, Geoeye-1 2011, Distribution Astrium Services

0.25
0.5 Kilometers 


\subsection{Discussion}

In the present study, the practical and conceptual approach of tele-epidemiology, which was developed by the CNES and its partners, was used to generate spatio-temporal high-resolution entomological risk maps for the presence of Aedes aegypti immature stages in Tartane, Martinique. The experimental unit was the single house and its close surroundings studied at a specific date. This unit was proven to be an appropriate scale for mapping risk, which is consistent with the suggestion that entomological dengue risk would best be measured at the household scale [38]. Environmental and meteorological data, which are synergetic drivers of mosquito presence and density, were both included for modeling the presence of dengue vector larvae. Ecological data has also been used as a surrogate for sociological and behavioral information. The resulting maps are examples of modeled entomological risk maps at the dwelling level with daily temporal resolution. These maps highlight the spatio-temporal variability among the houses that contained Aedes larvae-positive container(s).

\subsubsection{A Two-Step Approach}

A two-step approach was performed to closely link entomological modeling to the biological, physical, and societal mechanisms that drive (i) the presence of water-filled containers and (ii) larval development. Each step involved distinct physical and biological mechanisms, so these steps were separately considered. The presence of containers around houses is related to population behavior and socio-economic/socio-cultural aspects, whereas the presence of larvae in those containers is associated with ecological and meteorological factors that impact their biological cycle.

Modeling of the houses harboring one or several water-filled container(s) at a given date was achieved using two predictors from the Geoeye-1 image and one field meteorological variable. Firstly, the surface of the class "sparsely vegetated soil" in the house plot was positively associated with the water-positive experimental units. Secondly, the surface of the class "lawn" within the 50-m buffer around the house was negatively associated with the outcome. Both variables represent garden maintenance given that houses surrounded by lawn are likely to be well maintained. On one hand, containers or waste-bins that could be filled with precipitation should occur less frequently in well-maintained environments. On the other hand, an individual's socio-economic level may reflect the need to collect rainfall water in drum barrels to save money. In contrast, collecting rainfall may also be related to environmental-friendly behavior. Thirdly, the total rainfall during the 4-day period before the field visit was logically a risk factor for the presence of water-filled container(s) given that most of the containers, either intentionally or not, were filled with rainfall. Artificial filling of containers, which rarely happens, was not considered in this study. Nevertheless, large containers and drum barrels, which serve as major Aedes larval sites ( $82 \%$ of the total number of positive sites), were not artificially filled and were correctly accounted for in the analysis.

Modeling of the houses harboring one or several Aedes larvae-positive container(s) among the sampled houses having water-filled container(s) was achieved using one predictor from the Geoeye-1 image and one ground meteorological variable. Firstly, the surface of the class "asphalt" within the $50-\mathrm{m}$ buffer around the house was negatively associated with the outcome. This variable was strongly inversely correlated with the NDVI, which evaluates the density of vegetation. Many studies have 
highlighted the association between shade potentially provided by vegetation and the presence of Aedes immature stages $[30,39,40]$. Shade may lower the very high water temperatures that have been specifically recognized as a negative factor for the presence of Aedes aegypti larvae [3]. Vegetation may also provide nutrients for larvae via leaves falling in the water [41], whereas nectar could serve as food for adult mosquitoes [42]. In Martinique, Aedes aegypti is mainly endophilic, so vegetation probably does not serve as a resting site. Although the scale of the associations between shade and Aedes aegypti have been established at 2-3 m using ground data [40], the results of the present work corroborate previous studies that used remote-sensing images. Indeed, the presence of trees within a 30-m radius buffer zone was associated with adult Aedes aegypti abundance in Arizona [18], and niche modeling using Landsat 7 images (with $30-\mathrm{m}$ spatial resolution) predicted the areas suitable for Aedes aegypti breeding sites in Colombia [11]. Nonetheless, the class "asphalt" likely provided more information than a NDVI variable given that this class was retained in the final statistical model instead of any NDVI variable. Indeed, asphalt surroundings, which are related to high temperatures and evaporation, may also be unfavorable for allowing the breeding sites to persist long enough to be suitable for full cycle larval development. Secondly, the mean of maximum humidity for the 5-day period before the entomological record was positively associated with the presence of Aedes larvae-positive container(s) in the experimental units. The association was robust given that the variables for the 2- to 14-day period before the entomological record were also significantly associated with this outcome. Similar results were noted in Brazil [43] and Australia [44]. Humidity is positively correlated with precipitation and negatively correlated with evaporation. Thus, humidity may be related to an increased presence of water in the containers, thereby increasing the probability of complete larval development. This finding is consistent with previous works that have highlighted the association between rainfall and Aedes aegypti [45-48] or included rainfall data as predictive variable for modeling dengue risk [24].

\subsubsection{Scales and Resolutions}

Very high spatial resolution remote-sensing environmental variables and high temporal resolution ground meteorological variables were included. The ecological factors were temporally static (i.e., one value for the whole period), but they provided spatial dynamic as these variables were extracted from a very high spatial resolution satellite image (GeoEye-1 $0.41 \mathrm{~cm}$ ). The urban environment in Tartane remained quite stable during the studied period, justifying the use of one unique satellite image. On one hand, the majority of the LULC classes were appropriately defined by this unique image (buildings, asphalt, sea, swimming pools, sand, sugar cane, stubbles, and trees) given that they are not seasonally impacted. On the other hand, with regard to lawns, sparsely vegetated soil, and soil and vegetation indices that vary according the seasons, one unique image only provided a snapshot of the landscape. However, even static environmental data provide useful information for describing experimental units. Indeed, lawn and sparsely vegetated soils were identified as final explanatory variables at the first step of modeling, wherein environmental factors aimed to describe socio-economical and behavioral inputs. Using one unique image did not prevent from highlighting useful information; for example, the existence of a lawn during a dry season indicated that the garden was particularly well maintained, which reinforced the probability of the absence of water-filled containers. On the contrary, 
meteorological factors were spatially static (i.e., one value for the whole studied area was obtained from a ground observation station). However, these factors were extracted at a fine temporal scale (daily), thereby providing temporal dynamics. Regarding the size of the studied area, it was difficult to obtain variability in meteorological data apart from installing ground devices in the different sections or accessing ground radar data (about $1 \mathrm{~km}$ spatial resolution). Indeed, even remotely sensed rainfall data (e.g., Tropical Rainfall Measuring Mission (TRMM) and Rainfall Estimation (RFE)) do not provide heterogeneity in such small areas due to their spatial resolution $\left(0.25^{\circ}\right.$ for TRMM and RFE). Nevertheless, a recent study has revealed that it is crucial to consider the variability of rainfall amounts when modeling vector distribution, but the scales were beyond the size of the studied area [49].

\subsubsection{Accuracy and Validity of Models}

Given that the number of observations was limited, the validation was not based upon datasets different from those used to fit the models. The fact that $84 \%$ of the experimental units were correctly predicted is thus probably overestimated. The positive predictive value of the two-steps scenario was $57 \%$, and the negative predictive value was $90 \%$ (false positive rate $=43 \%$ and false negative rate $=10 \%$ ). From a larval control operational point of view, this scenario is very powerful to limit the amount of time spent on the ground by preventing the teams from visiting a large number of negative houses. However, the predictive ability to detect positive houses should be improved given that a large proportion of risky houses are missed.

Bias could have been introduced in the models given that ground data were not collected on the same dates for each section. In addition, some sections were preferentially investigated during rainy/dry seasons. Nevertheless, analysis of the resulting risk maps indicated that the sections that were followed mainly during rainy or dry seasons exhibited no particular pattern in terms of prediction of Aedes aegypti larvae presence. Indeed, although an entirely environmental model could not have been fitted due to this bias, the presence of meteorological variables in the models served as seasonal adjustment. In addition, the six sub-models which were fitted at both steps by separately omitting the experimental units of each section provided estimates similar to the final models. The latter indicates that none of the sections significantly modified the modeling results. Finally, the fact that the section effect was not significant at both steps of the analysis revealed that the explanatory variables managed to represent the environmental heterogeneity of the dataset.

\subsubsection{From Entomological Risk Maps to Ground Control Actions}

Models should be used to spatially and temporally prioritize prevention where the risk is the greatest [38]. On the one hand, entomological data are rarely collected in a routine fashion in a given area. When field studies are undertaken, they often provide only a snapshot of a continuous phenomenon. Risk maps are then expected to provide continuity for enhanced risk evaluation. On the other hand, maps that are available at the household level could facilitate the detection of "key premises" [50,51] for efficient control. Indeed, houses with an increased number of Aedes larvae-positive days in a month could be targeted for the destruction of breeding sites and dispersal of information to human populations to decrease the logistic burden. The resulting maps of the present study could subsequently be used as a tool for Aedes aegypti larvae control operational systems based 
on updated satellite images and meteorological information. Indeed, the equations resulting from the final models at both steps could be applied in the same area at other dates or even in other similar settings if the same LULC classes could be extracted from very high-resolution images. Although such image processing is time consuming, a unique image could be used to predict the entomological risk for several years in urban areas that are not experiencing rapid expansion. A prerequisite would involve testing the validity of any extrapolated predictions with new ground data. In any objective of using risk maps to assess dengue epidemiological risk, the association between the spatio-temporal distribution of immature stages and dengue disease should be evaluated in this area of Martinique. Indeed, a review paper highlighted various studies that have demonstrated this direct association as well as other studies that failed [25]. It is highly probable that additional layers of information should be added to those entomological maps, including pupal productivity or adult (infected) vector densities as well as human factors (acquired immunity, human-vector contact, population movement and distance to epidemic areas).

\section{Conclusions}

The present study revealed that environmental information at a fine spatial scale obtained using very high-resolution satellite images coupled with field meteorological data at a fine temporal scale were successfully highlighted as explanatory variables for the presence of Aedes aegypti larvae in Tartane, Martinique. Daily entomological predictive risk maps of the presence of Aedes aegypti larvae-positive container(s) were generated at the level of individual houses. As it has been often advocated, focusing interventions in the places and periods with maximum risk is paramount to enhanced allocation of limited resources and improved dengue control. In this context, such entomological risk maps may be considered as one of the tools available, and tele-epidemiology may be applied. Finally, the approach presented in this paper can be applied to assessments of the emerging chikungunya entomological risk levels in Martinique given that Aedes aegypti is also the vector for this disease [52].

\section{Acknowledgments}

The authors would like to thank David Flamanc from the DEAL Martinique (Direction de l'Environnement, de l'Aménagement et du Logement) for providing and permitting the full use of the Litto3D $^{\circledR}$ data. The authors acknowledge the SERTIT (SErvice Régional de Traitement d'Image et de Télédétection; Hervé Yésou, Carlos Uribe, Claire Huber) for providing inputs for the definition of the very high-resolution indices. VM, CV and JPL thank Sanofi-Pasteur for supporting part of this study (images purchasing, data analysis). VM and JPL also acknowledge CNES (Centre National d'Etudes Spatiales) for support. This is an LDEO contribution \#7843.

\section{Author Contributions}

VM, CV and JPL conceived and designed the experiments. VM, AY, ME, PP, MG, and JPL performed the experiments. VM, CV, MG, and JPL analyzed the data. VM, CV, YMT, and JPL contributed to the writing of the manuscript. 


\section{Conflicts of Interest}

The founding sponsor had no role in the design of the study; the collection, analyses or interpretation of data; the writing of the manuscript, or the decision to publish the results.

\section{References}

1. Murray, N.E.; Quam, M.B.; Wilder-Smith, A. Epidemiology of dengue: Past, present and future prospects. Clin. Epidemiol. 2013, 5, 299-309.

2. Christophers, S. Aedes Aegypti (L.) The Yellow Fever Mosquito: Its Life History, Bionomics and Structure; Cambridge University Press: Cambridge, UK, 1960.

3. Hemme, R.R.; Tank, J.L.; Chadee, D.D.; Severson, D.W. Environmental conditions in water storage drums and influences on Aedes aegypti in Trinidad, West Indies. Acta Trop. 2009, 112, 59-66.

4. Wan, S.W.; Lin, C.F.; Wang, S.; Chen, Y.H.; Yeh, T.M.; Liu, H.S.; Anderson, R.; Lin, Y.S. Current progress in dengue vaccines. J. Biomed. Sci. 2013, 20, doi:10.1186/1423-0127-20-37.

5. Tun-Lin, W.; Lenhart, A.; Nam, V.S.; Rebollar-Tellez, E.; Morrison, A.C.; Barbazan, P.; Cote, M.; Midega, J.; Sanchez, F.; Manrique-Saide, P.; et al. Reducing costs and operational constraints of dengue vector control by targeting productive breeding places: A multi-country non-inferiority cluster randomized trial. Trop. Med. Int. Health 2009, 14, 1143-1153.

6. Stefani, A.; Dusfour, I.; Corrêa, A.P.S.A.; Cruz, M.C.B.; Dessay, N.; Galardo, A.K.R.; Galardo, C.D.; Girod, R.; Gomes, M.S.M.; Gurgel, H.; et al. Land cover, land use and malaria in the Amazon: A systematic literature review of studies using remotely sensed data. Malar. J. 2013, 12, doi:10.1186/1475-2875-12-192.

7. Machault, V.; Vignolles, C.; Borchi, F.; Vounatsou, P.; Pages, F.; Briolant, S.; Lacaux, J.-P.; Rogier, C. The use of remotely sensed environmental data in the study of malaria. Geospat. Health 2011, 5, 151-168.

8. Yang, G.-J.; Vounatsou, P.; Zhou, X.-N.; Utzinger, J.; Tanner, M. A review of geographic information system and remote sensing with applications to the epidemiology and control of schistosomiasis in China. Acta Trop. 2005, 96, 117-129.

9. Kalluri, S.; Gilruth, P.; Rogers, D.; Szczur, M. Surveillance of arthropod vector-borne infectious diseases using remote sensing techniques: A review. PLoS Pathog. 2007, 3, 1361-1371.

10. Bergquist, N.R. Vector-borne parasitic diseases: New trends in data collection and risk assessment. Acta Trop. 2001, 79, 13-20.

11. Arboleda, S.; Jaramillo, O.N.; Peterson, A.T. Spatial and temporal dynamics of Aedes aegypti larval sites in Bello, Colombia. J. Vector Ecol. 2012, 37, 37-48.

12. Neteler, M.; Roiz, D.; Rocchini, D.; Castellani, C.; Rizzoli, A. Terra and Aqua satellites track tiger mosquito invasion: Modelling the potential distribution of Aedes albopictus in north-eastern Italy. Int. J. Health Geogr. 2011, 10, doi:10.1186/1476-072X-10-49.

13. Roiz, D.; Neteler, M.; Castellani, C.; Arnoldi, D.; Rizzoli, A. Climatic factors driving invasion of the tiger mosquito (Aedes albopictus) into new areas of Trentino, Northern Italy. PLoS One 2011, 6, e14800. 
14. Estallo, E.L.; Lamfri, M.A.; Scavuzzo, C.M.; Almeida, F.F.; Introini, M.V.; Zaidenberg, M.; Almiron, W.R. Models for predicting Aedes aegypti larval indices based on satellite images and climatic variables. J. Am. Mosq. Control Assoc. 2008, 24, 368-376.

15. Rotela, C.H.; Espinosa, M.O.; Albornoz, C.; Lafaye, M.; Lacaux, J.-P.; Tourre, Y.M.; Vignolles, C.; Scavuzzo, C. Desarrollo de mapas predictivos de densidad focal de Aedes aegypti en la ciudad de Puerto Iguazú (Argentina), basados en información ambiental derivada de imágenes SPOT 5 HRG1. In Proceedings of XIII Simposio Latinoamericano de Percepcion Remota y Sistemas de Informacion Espacial (SELPER), Havana, Cuba, 22-28th September 2008.

16. Fuller, D.O.; Troyo, A.; Calderón-Arguedas, O.; Beier, J.C. Dengue vector (Aedes aegypti) larval habitats in urban environment of Costa Rica analysed with ASTER and QuickBird imagery. Int. J. Remote Sens. 2009, 31, 3-11.

17. Vanwambeke, S.O.; Bennett, S.N.; Kapan, D.D. Spatially disaggregated disease transmission risk: Land cover, land use and risk of dengue transmission on the island of Oahu. Trop. Med. Int. Health 2011, 16, 174-185.

18. Landau, K.I.; van Leeuwen, W.J. Fine scale spatial urban land cover factors associated with adult mosquito abundance and risk in Tucson, Arizona. J. Vector Ecol. 2012, 37, 407-418.

19. Sarfraz, M.S.; Tripathi, N.K.; Tipdecho, T.; Thongbu, T.; Kerdthong, P.; Souris, M. Analyzing the spatio-temporal relationship between dengue vector larval density and land-use using factor analysis and spatial ring mapping. BMC Public Health 2012, 12, doi:10.1186/1471-2458-12-853.

20. Van Benthem, B.H.; Vanwambeke, S.O.; Khantikul, N.; Burghoorn-Maas, C.; Panart, K.; Oskam, L.; Lambin, E.F.; Somboon, P. Spatial patterns of and risk factors for seropositivity for dengue infection. Am. J. Trop. Med. Hyg. 2005, 72, 201-208.

21. Rotela, C.; Fouque, F.; Lamfri, M.; Sabatier, P.; Introini, V.; Zaidenberg, M.; Scavuzzo, C. Space-time analysis of the dengue spreading dynamics in the 2004 Tartagal outbreak, Northern Argentina. Acta Trop. 2007, 103, 1-13.

22. Neteler, M.; Metz, M.; Rocchini, D.; Rizzoli, A.; Flacio, E.; Engeler, L.; Guidi, V.; Luthy, P.; Tonolla, M. Is Switzerland suitable for the invasion of Aedes albopictus? PLoS One 2013, 8, e82090.

23. ECDC. Development of Aedes Albopictus Risk Maps ECDC Technical Report; European Centre for Disease Prevention and Control: Stockholm, Sweden, 2009.

24. Rogers, D.J.; Suk, J.E.; Semenza, J.C. Using global maps to predict the risk of dengue in Europe. Acta Trop. 2014, 129, 1-14.

25. Eisen, L.; Lozano-Fuentes, S. Use of mapping and spatial and space-time modeling approaches in operational control of Aedes aegypti and dengue. PLoS Negl. Trop. Dis. 2009, 3, e411.

26. Vignolles, C.; Lacaux, J.P.; Tourre, Y.M.; Bigeard, G.; Ndione, J.A.; Lafaye, M. Rift Valley fever in a zone potentially occupied by Aedes vexans in Senegal: Dynamics and risk mapping. Geospat. Health 2009, 3, 211-220.

27. Vignolles, C.; Tourre, Y.M.; Mora, O.; Imanache, L.; Lafaye, M. TerraSAR-X high-resolution radar remote sensing: An operational warning system for Rift Valley fever risk. Geospat. Health 2010, 5, 23-31. 
28. Lacaux, J.-P.; Tourre, Y.-M.; Vignolles, C.; Ndione, J.-A.; Lafaye, M. Classification of ponds from high-spatial resolution remote sensing: Application to Rift Valley fever epidemics in Senegal. Remote Sens. Environ. 2006, 106, 66-74.

29. Machault, V.; Vignolles, C.; Pagès, F.; Gadiaga, L.; Tourre, Y.M.; Gaye, A.; Sokhna, C.; Trape, J.-F.; Lacaux, J.-P.; Rogier, C.; et al. Risk mapping of Anopheles gambiae s.l. densities using remotely-sensed environmental and meteorological data in an urban area: Dakar, Senegal. PLoS One 2012, 7, e50674.

30. Tun-Lin, W.; Kay, B.H.; Barnes, A. The Premise Condition Index: A tool for streamlining surveys of Aedes aegypti. Am. J. Trop. Med. Hyg. 1995, 53, 591-594.

31. Nogueira, L.A.; Gushi, L.T.; Miranda, J.E.; Madeira, N.G.; Ribolla, P.E. Application of an alternative Aedes species (Diptera: Culicidae) surveillance method in Botucatu City, Sao Paulo, Brazil. Am. J. Trop. Med. Hyg. 2005, 73, 309-311.

32. Peres, R.C.; Rego, R.; Maciel-de-Freitas, R. The use of the Premise Condition Index (PCI) to provide guidelines for Aedes aegypti surveys. J. Vector Ecol. 2013, 38, 190-192.

33. Etienne, M. Etude de la bioécologie d'Aedes Aegypti à la Martinique en relation avec l'épidémiologie de la dengue, Ph. D. Thesis, Université de Montpellier I, Montpellier, France, 22 June 2006.

34. Yebakima, A. Control of Aedes aegypti in Martinique. Contribution of entomology studies. Bull. Soc. Pathol. Exot. 1996, 89, 161-162.

35. Rouse, J.W.; Hass, R.H.; Schell, J.A.; Deering, D.W. Monitoring vegetation systems in the Great Plains with ERTS. In Proceedings of the Third ERTS Symposium, Washington, DC, USA, 10-14 December 1973; NASA SP 351, pp. 309-317.

36. Tucker, C.J. Red and photographic infrared linear combinations for monitoring vegetation. Remote Sens. Environ. 1979, 8, 127-150.

37. McFeeters, S.K. The use of the normalised difference water index (NDWI) in the delineation of open water features. Int. J. Remote Sens. 1996, 17, 1425-1432.

38. Scott, T.W.; Morrison, A.C. Vector dynamics and transmission of dengue virus: Implications for dengue surveillance and prevention strategies: Vector dynamics and dengue prevention. Curr. Top. Microbiol. Immunol. 2010, 338, 115-128.

39. Vezzani, D.; Albicocco, A.P. The effect of shade on the container index and pupal productivity of the mosquitoes Aedes aegypti and Culex pipiens breeding in artificial containers. Med. Vet. Entomol. 2009, 23, 78-84.

40. Vezzani, D.; Rubio, A.; Velazquez, S.M.; Schweigmann, N.; Wiegand, T. Detailed assessment of microhabitat suitability for Aedes aegypti (Diptera: Culicidae) in Buenos Aires, Argentina. Acta Trop. 2005, 95, 123-131.

41. Reiskind, M.H.; Greene, K.L.; Lounibos, L.P. Leaf species identity and combination affect performance and oviposition choice of two container mosquito species. Ecol. Entomol. 2009, 34, 447-456.

42. Martinez-Ibarra, J.A.; Rodriguez, M.H.; Arredondo-Jimenez, J.I.; Yuval, B. Influence of plant abundance on nectar feeding by Aedes aegypti (Diptera: Culicidae) in southern Mexico. J. Med. Entomol. 1997, 34, 589-593. 
43. Favier, C.; Degallier, N.; Vilarinhos Pde, T.; de Carvalho Mdo, S.; Yoshizawa, M.A.; Knox, M.B. Effects of climate and different management strategies on Aedes aegypti breeding sites: A longitudinal survey in Brasilia (DF, Brazil). Trop. Med. Int. Health 2006, 11, 1104-1118.

44. Azil, A.H.; Long, S.A.; Ritchie, S.A.; Williams, C.R. The development of predictive tools for pre-emptive dengue vector control: A study of Aedes aegypti abundance and meteorological variables in North Queensland, Australia. Trop. Med. Int. Health 2010, 15, 1190-1197.

45. Wee, L.K.; Weng, S.N.; Raduan, N.; Wah, S.K.; Ming, W.H.; Shi, C.H.; Rambli, F.; Ahok, C.J.; Marlina, S.; Ahmad, N.W.; et al. Relationship between rainfall and Aedes larval population at two insular sites in Pulau Ketam, Selangor, Malaysia. Southeast Asian J. Trop. Med. Public Health 2013, 44, 157-166.

46. Baruah, S.; Dutta, P. Seasonal prevalence of Aedes aegypti in urban and industrial areas of Dibrugarh district, Assam. Trop. Biomed. 2013, 30, 434-443.

47. Duncombe, J.; Clements, A.; Davis, J.; Hu, W.; Weinstein, P.; Ritchie, S. Spatiotemporal patterns of Aedes aegypti populations in Cairns, Australia: Assessing drivers of dengue transmission. Trop. Med. Int. Health 2013, 18, 839-849.

48. Stewart Ibarra, A.M.; Ryan, S.J.; Beltran, E.; Mejia, R.; Silva, M.; Munoz, A. Dengue Vector Dynamics (Aedes aegypti) Influenced by Climate and Social Factors in Ecuador: Implications for targeted control. PLoS One 2013, 8, e78263.

49. Guilloteau, C.; Gosset, M.; Vignolles, C.; Alcoba, M.; Tourre, Y.M.; Lacaux, J.-P. Impacts of satellite-based rainfall products on predicting spatial patterns of Rift Valley fever vectors. J. Hydrometeorol. 2014, 15, 1624-1635.

50. Tun-Lin, W.; Kay, B.H.; Barnes, A. Understanding productivity, a key to Aedes aegypti surveillance. Am. J. Trop. Med. Hyg. 1995, 53, 595-601.

51. Chadee, D.D. Key premises, a guide to Aedes aegypti (Diptera: Culicidae) surveillance and control. Bull. Entomol. Res. 2004, 94, 201-207.

52. Simon, F.; Savini, H.; Parola, P. Chikungunya: A paradigm of emergence and globalization of vector-borne diseases. Med. Clin. North. Am. 2008, 92, 1323-1343.

(C) 2014 by the authors; licensee MDPI, Basel, Switzerland. This article is an open access article distributed under the terms and conditions of the Creative Commons Attribution license (http://creativecommons.org/licenses/by/4.0/). 